\title{
The cranial orbital buttress technique for nonsyndromic unicoronal and metopic craniosynostosis
}

\author{
Shane K. F. Seal, MD, FRCSC, ${ }^{1}$ Paul Steinbok, MD, FRCSC, ${ }^{2}$ and \\ Douglas J. Courtemanche, MD, MS, FRCSC'1
}

\begin{abstract}
Divisions of ${ }^{1}$ Plastic Surgery and ${ }^{2}$ Neurosurgery, Department of Surgery, University of British Columbia and British Columbia Children's Hospital, Vancouver, British Columbia, Canada
\end{abstract}

\begin{abstract}
OBJECT Current craniosynostosis procedures can result in complications due to absorbable plates and screws or other specialized expensive hardware. The authors propose the cranial orbital buttress (COB) technique of frontoorbital remodeling for metopic and unicoronal synostoses, wherein no plates or screws are used. They hypothesize that, with this technique, aesthetically acceptable outcomes for unicoronal and metopic synostosis can be achieved. In this article, they present this technique and compare the results with current frontoorbital remodeling practices.
\end{abstract}

METHODS The authors conducted a retrospective chart review of cases in which patients with nonsyndromic unicoronal or metopic synostosis underwent cranio-orbital surgery at their institution from 1985 through 2009. Operative parameters, surgical variations, and complications were analyzed. The COB technique uses a 1-piece switch, hemiforeheads, or multiple pieces for forehead remodeling. The supraorbital bar is reconstructed in patients with metopic synostosis using a double wedge or greenstick fracture technique, and in patients with unicoronal synostosis a hinge procedure based on a 1.5-orbital osteotomy is used. The supraorbital bar is advanced and supported in place by bone graft(s) inserted at the lateral aspect(s) of the orbit(s) to form a buttress, with fixation done using absorbable sutures.

RESULTS A total of 79 cases met the criteria for inclusion in the study. Twenty-nine patients had metopic synostosis, 3 had combined metopic and sagittal synostoses, and 47 had unicoronal synostosis. The patients' mean age at surgery was $11.4 \pm 10.1$ months and the mean operative time was $183.4 \pm 41.0$ minutes. The mean length of hospital stay was $3.7 \pm 1.2$ days. The mean blood loss was $150.0 \pm 125.6 \mathrm{ml}$, and $33 \%$ of patients required a blood transfusion (mean volume $206.9 \pm 102.3 \mathrm{ml})$. In metopic synostosis, hemiforeheads were used most often (24/29, 83\%), and the supraorbital bar was remodeled using a bilateral intracranial orbital osteotomy followed by a double wedge modification $(23 / 29,79 \%)$ or a greenstick fracture (4/29 14\%) for milder cases. Forehead remodeling for unicoronal synostosis was by a forehead switch $(39 / 47,83 \%)$ and the supraorbital bar was remodeled using a 1.5-orbital intracranial orbital osteotomy (34/47, $72 \%$ ) such that the bar was advanced on the abnormal side and hinged at the midline of the normal orbit. Perioperative complications occurred in $19 \%$ of cases and included dural tears $(16 \%)$, inconsequential subdural hematoma $(1.3 \%)$, and nasal greenstick fracture (1.3\%). The total reoperation rate was $7.6 \%$ (cranioplasties for irregular contours, $6.3 \%$; scar revision, 1.3\%).

CONCLUSIONS The COB remodeling technique is simple and efficient, gives acceptable outcomes, and is less resource intensive than previous techniques reported in the literature.

http://thejns.org/doi/abs/10.3171/2015.2.FOCUS14844

KEY WORDS craniosynostosis; trigonocephaly; frontal plagiocephaly; bone graft; operative technique; metopic synostosis; unicoronal synostosis

$\mathrm{C}$ RANIOSYNOSTOSIS is the premature closure of sutures in the cranial vault, and it occurs in 1 in 2500 births. ${ }^{24}$ Single-suture fusion is the most common and can occur with an unknown etiology (nonsyndromic) or with a syndromic etiology. Nonsyndromic craniosyn- ostoses may be associated with intracranial hypertension, visual impairment, disordered brain development, and neuropsychiatric disorders. ${ }^{33}$ The abnormal head shape depends on which suture has fused. In craniosynostoses involving metopic or unicoronal sutures, the deformities

ABBREVIATION COB = cranial orbital buttress.

SUBMITTED January 1, 2015. ACCEPTED February 27, 2015.

INCLUDE WHEN CITING DOI: 10.3171/2015.2.FOCUS14844.

DISCLOSURE Dr. Seal's craniofacial fellowship was funded by Stryker Leibinger. Dr. Courtemanche does not receive any royalties for the sale of Courtemanche templates. 
affect mainly the forehead, orbits, and face. Correction of these deformities improves neurodevelopment and appearance. ${ }^{2,28}$

Although orbital remodeling surgery is classically used to treat craniosynostosis, in recent years distraction osteogenesis $s^{11,14,31}$ and endoscopic techniques ${ }^{7,10,13}$ have been proposed. Distraction osteogenesis has the drawbacks of prolonged treatment time and need for a second operation, and risk of infection at hardware sites as well as the potential for dural tears. ${ }^{31}$ There may be some utility in endoscopic procedures when applied earlier, unlike the traditional open surgical approaches. ${ }^{1,7}$ To date, frontoorbital remodeling surgery remains the standard of care for metopic and unicoronal craniosynostosis treatment, with techniques varying between centers.

Paul Tessier's innovative work in 1967 established surgery as the acceptable treatment for craniosynostosis, and it remains the standard for metopic and unicoronal synostoses. ${ }^{32}$ This surgery, usually performed within the 1st year of life to correct the bony deformity and improve aesthetic appearance, involves excision of the fused suture and remodeling/repositioning of the frontal bone and orbits. The techniques for this procedure vary between centers. Tessier's tongue-in-groove advancement of the roof of the orbits followed by an attachment of a reconstructed forehead bone still remains one of the most commonly reported techniques. ${ }^{32}$

Since this groundbreaking work, surgical techniques have evolved. Hoffman and Mohr used Tessier's method combined with their own technique for advancing the lateral canthal segments of the supraorbital region for the treatment of metopic synostosis. ${ }^{12}$ Soon thereafter, Marchac and Renier published the "floating forehead" technique, later combined with a frontoorbital bandeau remodeling. Marchac advises use of the floating forehead technique for children under 6 months of age, while for children older than 6 months he utilizes a horizontal tongue-in-groove advancement. ${ }^{15-17,25}$ Although theoretically feasible, his floating forehead technique resulted in temporal hollowing, and surgeons have since modified it. ${ }^{9,18,19}$ The tongue-in-groove procedure is also not easily adapted to repositioning the supraorbital bar when rotation in the coronal plane (sagittal axis) is required.

Linton A. Whitaker and coauthors published Whitaker's technique on the correction of craniofacial dysostosis in $1977 . .^{38}$ In his technique, three-fourths of the abnormal orbit is osteotomized and advanced to become level with the normal orbit. ${ }^{38}$ A lateral bone graft between the advanced orbit and the temporal bone is fixed in place with wires and used to maintain the newly advanced position. ${ }^{38}$ Three years later, he published a modified technique in which the orbit advancement was completed with a bony Z-plasty at the lateral orbit or by a tongue-in-groove procedure with the resulting bone positions firmly wired. ${ }^{37}$

Remodeling techniques specific for the correction of metopic synostosis have been published within the last few years, including the shell technique,,$^{5}$ the cathedral dome procedure, ${ }^{21}$ and Lille's surgical technique of frontal reshaping and rotation of the superior and lateral orbital $\operatorname{rim} .{ }^{23}$

Currently, the majority of procedures have evolved from permanent plating systems, which were proven to result in calvarial growth disturbance and intracranial migration of hardware, ${ }^{4,20}$ to absorbable plates and screws. Despite this advance, there still remain risks of postoperative complications when using absorbable hardware. ${ }^{3}$ In a review of the use of resorbable plates and screws in 1883 craniofacial surgical cases, Eppley et al. reported device failure from breakage of the plates that required reoperation in the postoperative period $(0.3 \%)$ and delayed foreign body reactions $(0.7 \%)$ that resulted in swelling and/or cyst formation. ${ }^{6}$ Higher complication rates due to resorbable plates and screws were reported by Pearson et al. $(17 \%)^{22}$ and Sanger et al. (15.3\%), including palpable plates and an instance in which the absorbable plates were surgically removed due to erythema. ${ }^{26}$ Furthermore, there are the inherent challenges in nearly all surgeries and operative techniques: blood loss, extended surgical times, narrow application, or lack of an aesthetically acceptable result.

Herein we present the cranial orbital buttress (COB) technique of frontal orbital remodeling for metopic and unicoronal synostosis. The use of plates and screws is avoided in order to minimize operative complications, while preserving the structural integrity of the reconstructed frontoorbital region. The orbits are advanced, not using a traditional tongue-in-groove method, but by using bone grafts inserted at the lateral aspects of the orbits. The frontal bone is then attached to the advanced orbital bar and all fixation is done using absorbable sutures. This paper describes this technique and reviews the outcomes and complications including the surgical safety issues and overall aesthetic results.

\section{Methods}

This study was approved by the Clinical Research Ethics Board of the University of British Columbia.

\section{Patients}

A retrospective chart review was conducted on cases involving patients with nonsyndromic metopic and unicoronal craniosynostoses admitted to British Columbia Children's Hospital in Vancouver for cranio-orbital surgery from 1985 through 2009.

\section{Operative Technique}

\section{Exposure of the Cranial Bone and Orbits}

A modified stealth incision, with a linear incision at the vertex and zigzag incisions in the parietal regions, is marked and infiltrated with $0.25 \%$ lidocaine and 1:400,000 adrenaline. The incision is made with monopolar diathermy using a Stryker Colorado needle (Stryker). The bicoronal flap is elevated in the subperiosteal plane off the cranium and temporalis muscle down to the supraorbital ridge, the zygomaticofrontal suture, and nasofrontal suture. Bipolar cautery is used for soft tissue hemostasis. Unipolar cautery and bone wax is used for hemostasis on the cranium. The supraorbital nerve is freed from its groove or foramen as needed. The reflected scalp flap is covered with microfibrillar collagen applied via a large syringe and then covered with moist gauze sponges. 


\section{Forehead Reconstruction}

With full exposure achieved, the reconstruction of the forehead can be planned. For metopic synostosis, the forehead is identified as two hemiforeheads within the bifrontal craniotomy. In unicoronal synostosis, a forehead switch is used, whereby the new forehead is defined in the frontal-parietal cranium.

Marchac templates (Template Frontal Marchac for Infants \& Babies, Marchac Instruments, Falcon Medical Polska) are used to define the new 1-piece forehead in unicoronal synostosis. Courtemanche templates (Biomet) are used to define the hemiforeheads to be found within the cranium in metopic synostosis. A bifrontal craniotomy is then marked out, incorporating the pieces to be used for the remodeled forehead. Anteriorly, the line for the supraorbital cranial cut is marked at 1 or $1.5 \mathrm{~cm}$ above the orbital rims based on the 3D contour and anticipating the site of the sphenoid wing.

Bur holes are made in the frontal bones just above the lateral orbital rim immediately superior to the sphenoid ridge. Additional bur holes are made superomedially behind the coronal suture if fused (coronal), or holes are made anteriorly when the coronal suture is open (metopic). When the anterior fontanel is still open, superomedial bur holes are not made; rather, the lateral edges of the fontanel are dissected off the dura.

The bifrontal cranial bone flap is then cut with a highspeed guarded side-cutting bur, with care taken to avoid a dural tear. Dissection of the dura away from the bone is carried out into the temporal regions below the sphenoid ridge. In cases of unicoronal synostosis where there is a temporal bulge, the bone is removed from the temporal fossa, recontoured, and replaced.

\section{Management of the Supraorbital Bar}

The floor of the anterior cranial fossa and the roof and lateral wall of the orbits are exposed. Osteotomies are then performed according to the synostosis type and the unique presentation of each abnormality.

Metopic: Bilateral Intracranial Orbital Osteotomy and Double Wedge. A bilateral intracranial orbital osteotomy is cut through the orbital roofs, across the forehead just above the nasofrontal suture, through the lateral wall of the orbit, and through the lateral orbital buttress (Fig. 1).

The supraorbital bar is then modified on a separate table. A double wedge osteotomy is cut in the supraorbital bar. The first is to elevate the lateral orbit such that the supraorbital margin is level and the second allows advancement of the lateral orbits (Fig. 2). Finally, the lateral margin of the orbital rim may be shaved to achieve a normal contour if required.

Unicoronal Synostosis: Intracranial 1.5-Orbital Osteotomy. In unicoronal synostosis, the supraorbital bar is repositioned and recontoured via a 1.5-orbital osteotomy. The osteotomy extends from the lateral buttress of the retruded orbit, across the forehead above the nasal frontal suture to the midpoint of the normal orbit (Fig. 3A). The roof of the normal orbit is then cut sagittally so that only the bone above the brow is intact (Fig. 3B). This allows the 1.5 orbits to hinge, with the advancement being maximal at the orbital buttress of the abnormal side (Fig. 3C). There is enough flex in the supraorbital bar to allow for $3 \mathrm{D}$ contouring if required.

Early cases in this series had a single-orbital osteotomy and advancement with the hinge point in the midline (1-orbital osteotomy). All osteotomies are performed with a high-speed side-cutting bur without a guard. The lateral orbital osteotomy is completed with an osteotome.

\section{Reconstruction of the Supraorbital Bar-Metopic and Unicoronal Synostosis}

The supraorbital bar is secured at the nose in the desired position. The amount of lateral advancement is measured and bone grafts from cranial bone are used to hold and support this degree of either unilateral (unicoronal) or bilateral (metopic) advancement. Grooves are made at the back of the lateral edge of the orbital bar and into the orbital buttress to allow the bone grafts to sit in a tonguein-groove style (Fig. 4). Drill holes are made in the bone grafts, the supraorbital bar, and the lateral buttress such that the bone grafts can be secured with a 2-0 Vicryl lacing suture (Fig. 4). Lateral canthopexy sutures, using 3-0 Vicryl through drill holes in the advanced orbital bar are used to support the new position of the lateral canthus (Fig. 4).

Greenstick Technique for Mild Metopic Synostosis. In milder metopic deformities, the osteotomies of the orbits can be left incomplete across the root of the nose allowing the orbital advancement to hinge (greenstick) at the nasion. The resulting flat contour of the central portion of the supraorbital bar can be reinforced with a bone graft secured tightly against the inner table (Fig. 5). This transverse strut of bone is secured with 2-0 Vicryl sutures to maintain the desired contour. The lateral orbital advancement is supported in the same way with the orbital buttress bone graft and lacing suture (Fig. 5).

\section{Contouring of the Forehead}

Construction of the forehead is performed on a separate sterile table. The forehead can be in 1, 2, or 3 segments, depending on initial templating as previously described. Contour modifications are performed as necessary using a Tessier bone bender (KLS-Martin). If more than 1 segment is used, the pieces are sutured together through drill holes using 2-0 Vicryl figure-of-eight sutures (Fig. 6). Small strut grafts provide contour stability (Fig. 6). The newly constructed forehead is secured with 2-0 Vicryl to the supraorbital bar with vertical locking sutures to maintain edge alignment (Fig. 7).

The remaining calvarial bone is then split apart using a Tessier bone bender to squeeze the bone and shear the outer from the inner table. A sharp osteotome may be required to complete the separation. ${ }^{30}$ The bone fragments are then used to fill temporal hollowing and cover exposed dura. The bone grafts used to fill temporal hollowing are secured anteriorly with 3-0 Vicryl and "hinged" in place (Fig. 8). Large fragments used to cover dura are secured to the forehead with drill holes and 3-0 Vicryl. Finally, any remaining bone fragments are morselized and placed on top of the dura (Fig. 8).

\section{Closing and Postoperative Care}

The coronal flap is pulled back over the reconstructed 


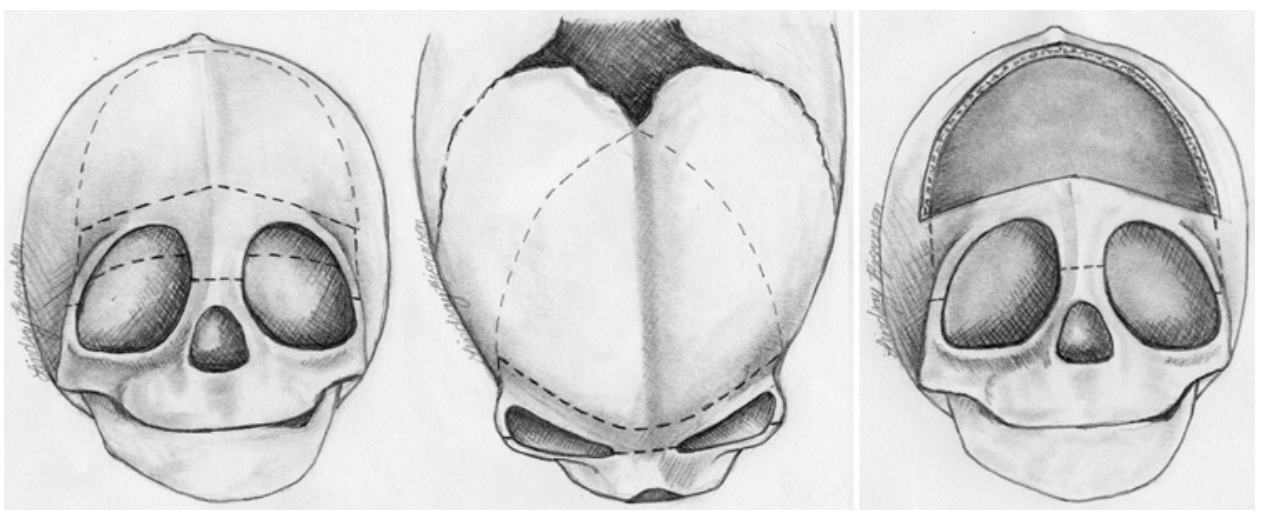

FIG. 1. Left: Craniotomy and bilateral intracranial orbital osteotomy in metopic synostosis. The 2 halves of the frontal bone will be switched to make the new forehead. Right: Bilateral intracranial orbital osteotomy in metopic synostosis shown with craniotomy completed. Copyright Lindsay Bjornson. Published with permission.

supraorbital bar and forehead to give complete periosteal coverage of the reconstruction. Specific attention is directed to ensuring adequate soft tissue advancement over the supraorbital bar. The galea is closed with interrupted 3-0 Vicryl sutures, and the scalp is closed with a running 4-0 Vicryl Rapide suture. No drains are inserted.

Finally, the wound is sealed with OpSite spray (Smith $\&$ Nephew). No dressing is applied. The patient is brought to the recovery room following extubation and is transferred to the ward later that day. Intensive care unit admission is not part of our routine protocol.

\section{Data Collection}

Patient data were entered into an electronic database and identified via the study's alphanumeric coding system. Demographics were collected, including sex, date of birth, date of admission, date of surgery, and date of discharge. Operative parameters recorded included time of incision, time of closure, blood loss, and amount of blood transfusion. Surgical technique details recorded included type of supraorbital advancement, type of forehead reconstruction, and type of supraorbital reconstruction. Finally, both intraoperative and hospital stay complications as well as any additional secondary surgeries were recorded.

\section{Statistical Analysis}

Descriptive statistics were used to evaluate surgical parameters and resulting complications (means, standard deviations, proportions). To determine statistical significance between parameters, the Student t-test was performed at the $95 \%$ confidence level $(\mathrm{p}<0.05)$.

\section{Results}

\section{Patients}

A total of 82 patients underwent surgery for metopic or unicoronal synostosis between September 1985 and June 2009 at our institution. Of these patients, 3 were excluded from this final analysis: 1 had Saethre-Chotzen syndrome, 1 had multiple suture involvement, and 1 had incomplete records regarding estimated surgical blood loss. Thus 79 cases were included in our analysis.

The study group included 41 male and 38 female patients. Twenty-nine patients had metopic synostosis, 3 patients had combined metopic and sagittal synostoses, and 47 patients had unicoronal synostosis.

The patients' mean age at surgery was 11.4 months (SD 10.1 months). The mean length of hospital stay was 3.7 days (SD 1.2 days). Follow-up occurred at 2 weeks, 6

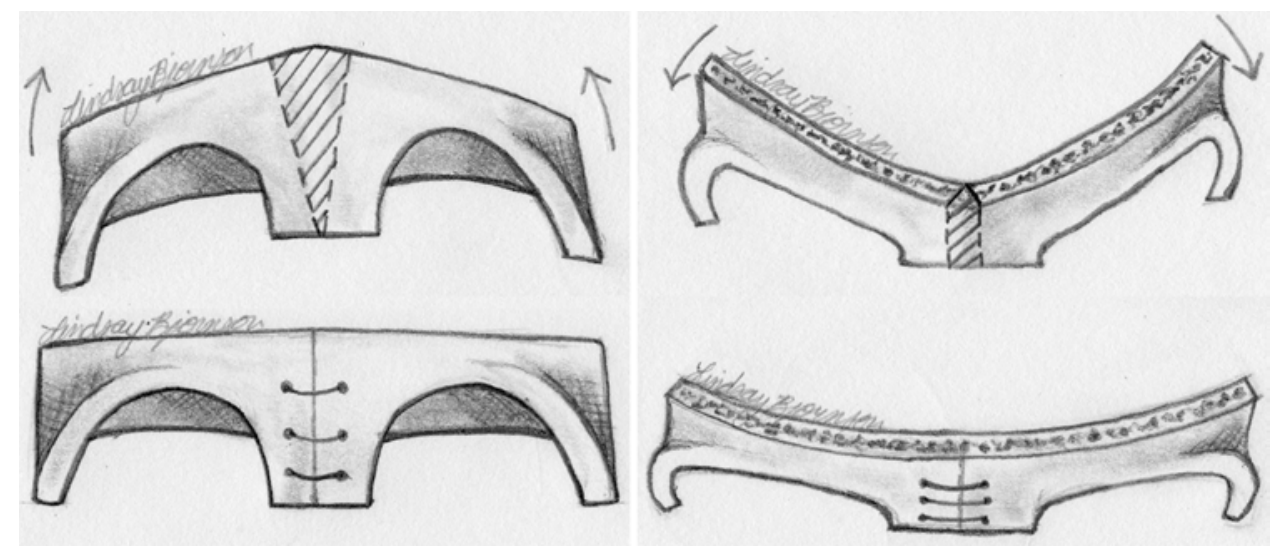

FIG. 2. Left: Wedge closing superiorly to level the supraorbital margin. Right: First wedge closing anteriorly to close the lateral orbits. Copyright Lindsay Bjornson. Published with permission. 

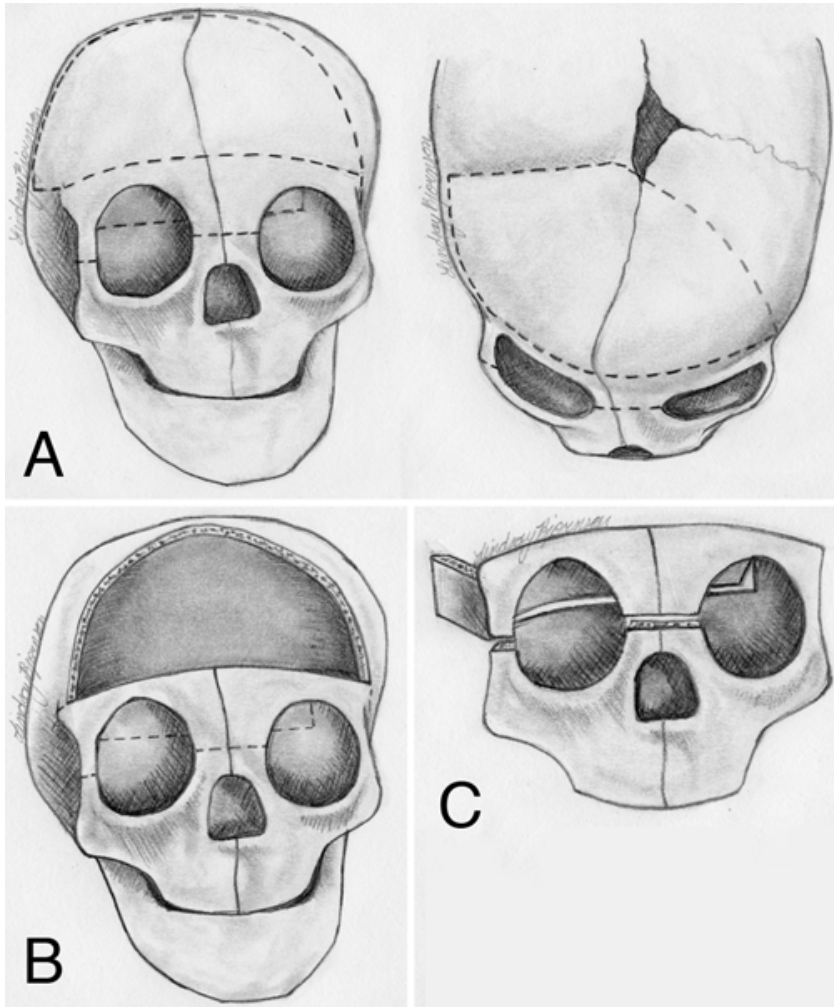

FIG. 3. A: A 1.5-orbital intracranial orbital osteotomy. B: A 1.5-orbital intracranial orbital osteotomy shown with craniotomy. C: Advancement of supraorbital bar. Copyright Lindsay Bjornson. Published with permission.

weeks, 3 months, 6 months, 1 year, 2 years, 3 years, and 5 years after surgery.

\section{Operative Parameters}

The mean operative time, defined as the period from incision to wound closure, was 183.4 minutes (SD 41.0 minutes). The mean blood loss was $150.0 \mathrm{ml}$ (SD 125.6 $\mathrm{ml})$. The total number of patients requiring blood transfusions was 26, and the mean volume of of packed red cell transfusions was $206.9 \mathrm{ml}$ (SD $102.3 \mathrm{ml}$ ). Specific dif-

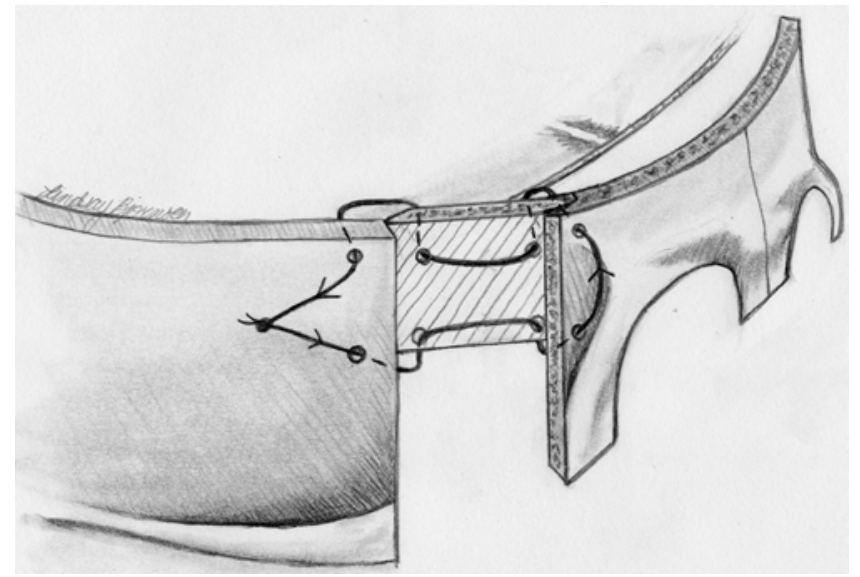

FIG. 4. Lacing suture used to hold supraorbital advancement in place. Copyright Lindsay Bjornson. Published with permission.

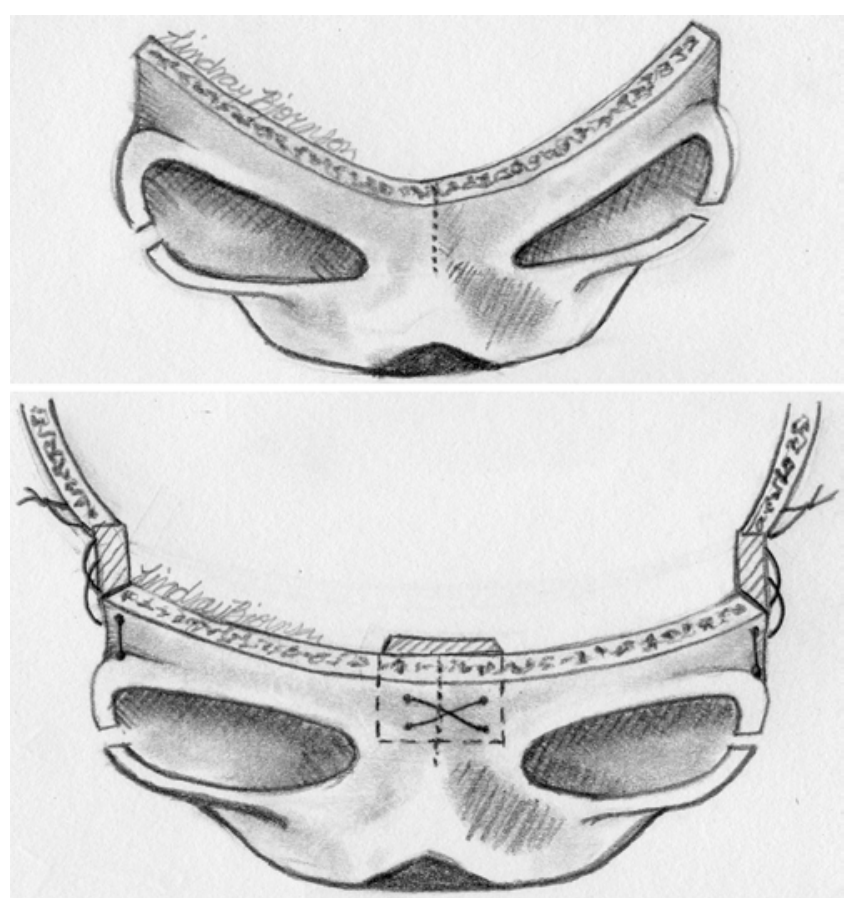

FIG. 5. Greenstick fractured supraorbital bar (upper) with placement of bone grafts at midline and lateral orbits (lower). Copyright Lindsay Bjornson. Published with permission.

ferences in operative parameters according to synostosis type are reported in Table 1.

Blood transfusion was performed in $33 \%$ of the cases (26 of 79) and was most frequent in patients with metopic synostosis, corresponding with the largest mean blood loss $(207.8 \mathrm{ml})$ and the largest blood transfusion volume (224.4 ml) (Table 1). Furthermore, the mean operative time was longer for metopic synostosis (202.8 minutes) than for unicoronal synostosis (169.2 minutes). The trends for patients with metopic and sagittal synostoses were similar to those for patients with metopic synostosis, but the sample size was small (3 patients) (Table 1).

In contrast to patients with metopic synostosis, in patients with unicoronal synostosis, blood was transfused $13 \%$ of the time. This rate of transfusion corresponds with a shorter operative time and less overall blood loss. There

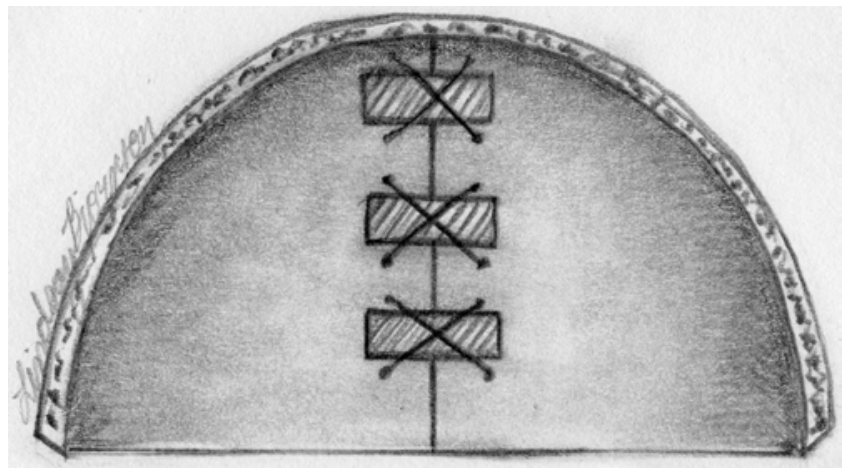

FIG. 6. Hemiforeheads secured with small strut grafts and figure-ofeight sutures. Copyright Lindsay Bjornson. Published with permission. 


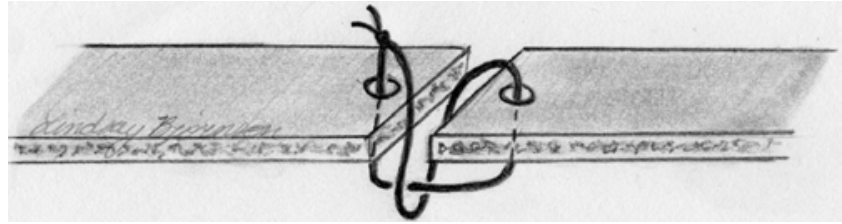

FIG. 7. Vertical locking suture. Copyright Lindsay Bjornson. Published with permission.

was no statistically significant relationship between overall length of stay at the hospital and operative time.

\section{Operative Technique}

Variations in forehead reconstruction, supraorbital bar reconstruction, and frontal orbital advancement were analyzed with respect to each type of synostosis (Table 2).

In 24 (83\%) of the 29 patients with metopic synostosis, hemiforeheads were used for reconstruction and a bilateral intracranial orbital osteotomy was used to remove the supraorbital bar for modification at a separate table (Table 3 ). For milder metopic synostosis the supraorbital bar was greenstick fractured. A bilateral advancement was exclusively used in patients with metopic synostosis and those with metopic and sagittal synostosis.

For 2 very mild metopic cases and 1 very severe metopic case, a different technique was used. For 1 very mild case, the supraorbital bar was greenstick fractured in situ, and in the other, the supraorbital bar was not modified at all. In the patient with very severe metopic synostosis, the supraorbital bar was replaced with a bone graft.

In the 47 patients with unicoronal synostosis, the predominant forehead reconstruction method was a forehead switch (used in 39 cases [83\%]), and the supraorbital bar hinge position was made at the midpoint of the normal orbit, defined as a 1.5-orbital osteotomy (see Fig. 3), in 34 patients (72\%). In 10 (21\%) of the patients with unicoronal synostosis, the hinge position occurred at the midpoint between the orbits (1-orbital osteotomy). In only 3 (6\%) of the cases was a complete bilateral intracranial orbital osteotomy performed to allow 3D repositioning of the supraorbital bar around the sagittal axis. A unilateral advancement was exclusively used for unicoronal synostosis surgeries.

\section{Complications and Outcomes}

Perioperative complications (dural tears, subdural hematoma, nasal greenstick fracture) and reoperations (cranioplasties and scar revision) were recorded for all 79 cases. Each complication was analyzed according to syn-

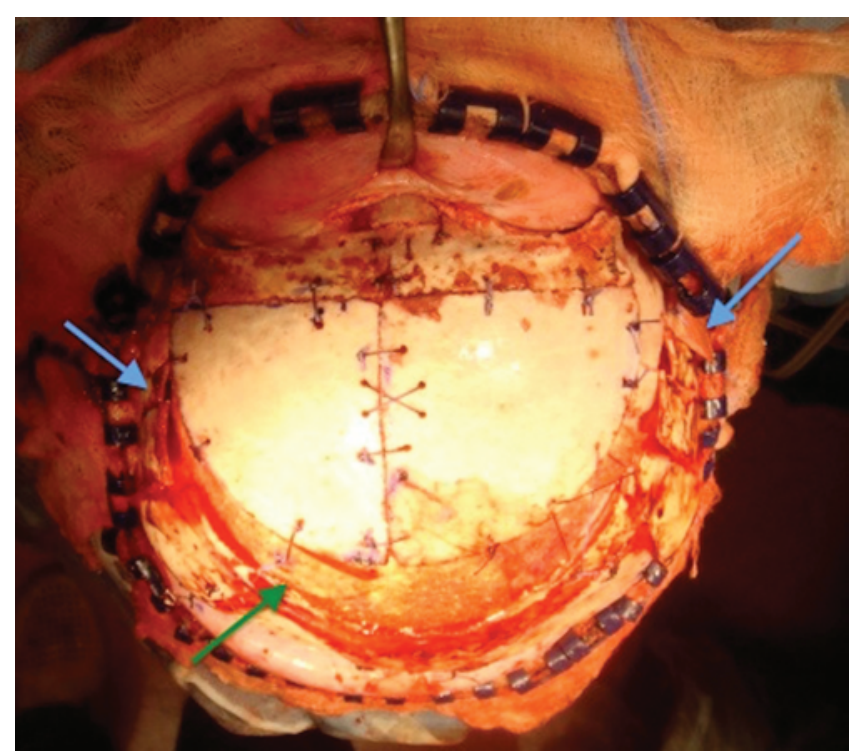

FIG. 8. Intraoperative photograph showing newly constructed forehead secured to supraorbital bar, bone grafts hinged to the forehead to fill temporal hollows (blue arrows), and split cranial bone grafts secured to cover the dura mater (green arrow).

ostosis type (Table 4) as well as the variation in forehead reconstruction (Table 5) and supraorbital bar management (Table 6).

There were 15 perioperative complications; most of these complications (13 of 15) were dural tears, all of which were identified and repaired intraoperatively. Other noted complications were a minimal left acute subdural hematoma noted through the intact dura after removal of the cranial flap and nasal greenstick fracture. No patients were returned to the operating room in the perioperative period.

In the longer term, $6(8 \%)$ of 79 patients underwent repeat surgery. In 5 patients, subsequent onlay hydroxyapatite cranioplasty was performed to correct anterior temporal contour irregularities, and 1 patient required 2 additional operations for a widened scalp scar. No cranial defects were observed following surgery. No statistically significant relationship was found between complication rate and type of synostosis.

\section{Discussion}

Our results show that the cranial orbital buttress (COB) technique is a simple, effective method with minor complications and satisfactory aesthetic outcomes due to few

TABLE 1. Operative parameters

\begin{tabular}{|c|c|c|c|c|c|c|c|c|}
\hline \multirow[b]{2}{*}{ Synostosis } & \multirow[b]{2}{*}{ No. of Pts } & \multirow{2}{*}{$\begin{array}{l}\text { Mean Age } \\
\text { at Op (mos) }\end{array}$} & \multirow{2}{*}{$\begin{array}{c}\text { Mean LOS } \\
\text { (days) }\end{array}$} & \multirow{2}{*}{$\begin{array}{c}\text { Mean Op } \\
\text { Time (min) }\end{array}$} & \multicolumn{3}{|c|}{ Blood Transfused } & \multirow[b]{2}{*}{ Mean Blood Loss (ml) } \\
\hline & & & & & Yes & No & Mean Vol (ml) & \\
\hline Metopic & 29 & 10.4 & 3.9 & 202.8 & 17 & 12 & 224.4 & 207.8 \\
\hline Metopic \& sagittal & 3 & 23.9 & 3.3 & 218.0 & 3 & 0 & 210.0 & 200.0 \\
\hline Unicoronal & 47 & 11.3 & 3.6 & 169.2 & 6 & 41 & 155.8 & 111.2 \\
\hline Average (SD) & NA & $11.4(10.1)$ & $3.7(1.2)$ & $183.4(41.0)$ & 26 & 53 & $206.9(102.3)$ & $150.0(125.6)$ \\
\hline
\end{tabular}

LOS = length of stay; NA = not applicable; pts = patients. 
TABLE 2. Forehead reconstruction

\begin{tabular}{lrccc}
\hline & & \multicolumn{3}{c}{ Forehead Reconstruction } \\
\cline { 3 - 5 } \multicolumn{1}{c}{ Synostosis } & No. of Pts & Switch & Hemiforeheads & Pultiple \\
\hline Metopic & 29 & 4 & 24 & 1 \\
\hline Metopic \& sagittal & 3 & - & 3 & - \\
\hline Unicoronal & 47 & 39 & 8 & - \\
\hline Total & 79 & $43(54 \%)$ & $35(44 \%)$ & $1(1 \%)$ \\
\hline
\end{tabular}

reoperations. We have further demonstrated that the $\mathrm{COB}$ technique is generally applicable to treat metopic, combined metopic and sagittal, and unicoronal synostosis at varying degrees of severity. The wide scope of the $\mathrm{COB}$ technique is rooted in its specific technical modifications for forehead and supraorbital bar remodeling based on the unique demands of each individual case.

\section{Operative Parameters}

The mean age of the patients at surgery in this series was 11.4 months, which is consistent with the timeline typical for frontoorbital remodeling. ${ }^{27}$ This differs from distraction osteogenesis, which proceeds as early as 5 months, and endoscopic treatments, which typically occur at 3 months of age or earlier. ${ }^{11,13}$ Selber et al. (2008) suggested that frontoorbital remodeling for unilateral advancement should be delayed until 6 months of age in order to avoid retrusion, ${ }^{27}$ and more recently Utria et al. (2014) published similar findings, suggesting 6-12 months as the optimal time for cranial vault remodeling. ${ }^{34}$

Our patients' mean length of stay in the hospital was 3.7 days, and this time was comparable to that required with other surgical techniques for craniosynostosis. ${ }^{3,8,11} \mathrm{~A}$ mean operative time of 183.34 minutes was determined for the COB technique, with metopic synostoses and combined metopic and sagittal synostoses requiring longer operations than unicoronal synostoses. Overall, this operative time is significantly shorter than that required for complex craniectomies (4-8 hours) and for the tongue-in-groove procedure (4 hours) $)^{37}$ but within the 2-3 hour timeline of Whitaker's original 1977 procedure. ${ }^{38}$ Although endoscopic procedures are faster, they remain technically limited..$^{13,35}$

Blood was transfused in $33 \%$ of all patients undergoing operations. In comparison to the patients in the unicoronal synostosis group, the metopic synostosis and metopic and sagittal synostosis patients, on average, lost more blood; moreover, transfusions were required by a higher proportion of patients with metopic synostosis and combined metopic and sagittal synostosis. Although blood loss has been considered universally acceptable for complex craniofacial procedures, ${ }^{13}$ Steinbok et al. reported that with simple intraoperative techniques and acceptance of low postoperative hemoglobin levels transfusion rates could be kept low without compromising patient safety. ${ }^{29}$ This approach combined with our technique resulted in a low blood transfusion rate.

\section{Operative Technique}

The COB technique fits the demanded specificity of each type and severity of synostosis through the variations in reconstruction of the forehead and management of the supraorbital bar. In fact, when Whitaker first published his technique, he found this lateral orbital advancement method to be applicable to both unilateral and bilateral deformities. ${ }^{38}$ While the bone graft principle in the COB technique is inspire by Whitaker's original technique, the osteotomies are different, and the fixation is completed with resorbable sutures rather than wires. ${ }^{38}$ Whitaker's osteotomies encircled three-fourths of the orbit inside and out, leaving it hinged on the nasolacrimal duct and the infraorbital nerve area whereas the osteotomies used in the COB technique only involved the supraorbital bar and for unicoronal synostosis, the hinge is made 1.5 orbits away from the lateral side of the abnormal orbit.

The COB technique can be used to treat a range of severity in metopic synostosis. The double-wedge modification technique was used for more severe cases (23/29, $80 \%$ ) whereas the greenstick fracture technique was used for the more moderate cases $(4 / 29,14 \%)$. There were 2 cases in which the metopic synostosis was very mild. In one, the supraorbital bar was greenstick fractured in situ and in the second, the supraorbital bar was advanced without modification.

In Lille's surgical technique, as described by Pellerin et al., ${ }^{23}$ metopic synostosis is corrected by frontal reshaping and rotation of the superior and lateral orbital rim. However, while no reoperations were required, the authors did not review intraoperative and postoperative complications. Furthermore, fixation was done with wire sutures and blood transfusion was considered inherent to the surgery.

In the present series, the forehead switch was the forehead reconstruction technique most frequently used in patients with unicoronal synostosis $(39 / 47,83 \%)$ and the su-

TABLE 3. Management of the supraorbital bar

\begin{tabular}{|c|c|c|c|c|c|c|}
\hline \multirow[b]{2}{*}{ Synostosis } & \multirow[b]{2}{*}{ No. of Pts } & \multirow{2}{*}{$\begin{array}{l}\text { Greenstick \& } \\
\text { Midline Graft }\end{array}$} & \multicolumn{2}{|c|}{ In Situ Modification } & \multirow[b]{2}{*}{ Double Wedge } & \multirow[b]{2}{*}{ Bilateral Orbital Osteotomy } \\
\hline & & & 1 Orbit & 1.5 Orbits & & \\
\hline Metopic & $29^{*}$ & $4 \dagger$ & - & - & 23 & - \\
\hline Metopic \& sagittal & 3 & 2 & - & - & 1 & - \\
\hline Unicoronal & 47 & - & 10 & 34 & - & 3 \\
\hline Total & 79 & $6 / 79(8 \%)$ & $10 / 79(13 \%)$ & $34 / 79(43 \%)$ & $24 / 79(30 \%)$ & $3 / 79(4 \%)$ \\
\hline
\end{tabular}

* Includes 1 very mild case wherein supraorbital bar was advanced without remodeling and 1 severe case wherein the supraorbital bar was replaced with a bone graft.

$†$ One mild metopic case allowed for greenstick fracturing in situ. 
TABLE 4. Complications and outcomes according to synostosis

\begin{tabular}{|c|c|c|c|c|c|c|}
\hline \multirow[b]{2}{*}{ Synostosis } & \multicolumn{3}{|c|}{ Perioperative Complications } & \multicolumn{2}{|c|}{ Reoperations } & \multirow[b]{2}{*}{ Total } \\
\hline & Dural Tear & Subdural Hematoma & Nasal Greenstick Fracture & Cranioplasty* & Scar Revision & \\
\hline Metopic & 4 & - & - & 1 & - & $5 / 29(17 \%)$ \\
\hline Metopic \& sagittal & 1 & - & - & - & - & $1 / 3(33 \%)$ \\
\hline Unicoronal & 8 & 1 & 1 & 4 & 1 & $15 / 47(32 \%)$ \\
\hline Grand total & $13(16 \%)$ & $1(1 \%)$ & $1(1 \%)$ & $5(6 \%)$ & $1(1 \%)$ & $21 / 79(27 \%)$ \\
\hline
\end{tabular}

* Correction of contour irregularities.

praorbital bar was remodeled with a 1.5-orbital osteotomy in the majority of cases $(34 / 47,72 \%)$. While the 1-orbital osteotomy was used in earlier cases, the 1.5-orbital hinge position was preferred due to additional stability and improved aesthetic results.

\section{Complications and Outcomes}

Complications encountered during surgery included: dural tears (16\%), an inconsequential subdural hematoma $(1.3 \%)$, and a nasal greenstick fracture (1.3\%). Dural tears occurred irrespective of type of synostosis and were related to the removal of the frontal bone flap. Esparza and Hinojosa's review of cases involving over 300 patients treated for craniosynostosis reported a rate of dural tears of approximately 5\%. While the rate of dural tears was lower than our own, they also had a higher complication rate for subcutaneous hemaatoma (6\%) and cerebrospinal fluid leakage (3\%) and infection (8\%). ${ }^{8}$

Any postoperative hardware complications were avoided in our cases by negating the use of hardware altogether. In distraction osteogenesis, local infections may occur at the sites were the rods penetrate the scalp, ${ }^{11}$ and in Selber and colleagues' study of frontal orbital reconstruction $7 \%$ of patients aged 12 months and older had hardware complications.

The low rates of reoperation (6\%) for cranial deformity ( $0 \%$ for cranial defects) and the need for scar revision in only 1 case show that the COB technique is an efficient and aesthetically successful procedure. In an analysis of surgical timing and complications, Whitaker and colleagues concluded that for unilateral orbital remodeling done at less than 12 months of age, a reoperation rate less than $10 \%$ should be expected, and for bilateral orbital osteotomies, a reoperation rate less than $50 \%$ was expected. ${ }^{36}$ The reoperation rate of $6 \%$ in this series is well within the acceptable range.

Not only is our technique straightforward, efficient, and safe, but there are also economic benefits. Up to now, absorbable plate fixation, costing many hundreds of dollars, has remained the common method for frontoorbital fixa- tion. However, our technique uses 2-0 Vicryl to hold the advancement in place, and the cost at our institution for a package of eight 2-0 Vicryl sutures is less than $\$ 1.00$ CDN. The cost difference between using an absorbable plating system and our technique is important for surgical budgets and for this technique's application in developing countries.

\section{Limitations of the COB Technique}

There was 1 case of metopic synostosis where the deformity was so severe that it was determined that the supraorbital bar could not be remodeled or advanced using the COB technique. Instead it was replaced with one built from calvarial bone grafts. A traditional tongue-in-groove procedure would have also failed, as no advancement of the supraorbital bar was possible given the nature of the deformity. Aesthetic outcomes were assessed by the plastic surgeon (D.C.). We acknowledge some bias in the decision regarding reoperation, and although 5 subsequent onlay cranioplasties are an indirect measure of initial outcomes, a more objective means of assessing outcomes, such as cephalic measurements or patient satisfaction surveys, would support our report of low rates of revision and aesthetic outcomes.

\section{Conclusions}

To our knowledge, this is the first report to describe the COB technique for frontoorbital advancement for nonsyndromic unicoronal and metopic synostoses. Our model is architecturally advanced such that no plates or screws are needed-instead, fixation of the frontal bones and orbit is done with a simple lacing pattern using absorbable sutures. This method is not only broadly applicable, but it also allows for subtle technical variations to optimize treatment and aesthetic outcomes for individual patients. Without the need for plates and screws, the COB technique is simple, efficient, gives acceptable outcomes, and is less resource intensive than previous techniques reported in the literature.

TABLE 5. Complications and outcomes according to forehead reconstruction

\begin{tabular}{|c|c|c|c|c|c|c|}
\hline \multirow[b]{2}{*}{ Reconstruction } & \multicolumn{3}{|c|}{ Perioperative Complications } & \multicolumn{2}{|c|}{ Reoperations } & \multirow[b]{2}{*}{ Total } \\
\hline & Dural Tear & Subdural Hematoma & Nasal Greenstick Fracture & Cranioplasty* & Scar Revision & \\
\hline Switch & 7 & 1 & 1 & 3 & 1 & $13 / 42(31 \%)$ \\
\hline Hemiforeheads & 6 & - & - & 2 & - & $8 / 36(22 \%)$ \\
\hline Multiple & - & - & - & - & - & $0 / 1(0 \%)$ \\
\hline
\end{tabular}


TABLE 6. Complications and outcomes according to supraorbital bar management

\begin{tabular}{|c|c|c|c|c|c|c|}
\hline \multirow[b]{2}{*}{ Supraorbital Bar Management } & \multicolumn{3}{|c|}{ Surgical Complications } & \multicolumn{2}{|c|}{ Reoperations } & \multirow[b]{2}{*}{ Total } \\
\hline & $\begin{array}{l}\text { Dural } \\
\text { Tear }\end{array}$ & $\begin{array}{l}\text { Subdural } \\
\text { Hematoma }\end{array}$ & $\begin{array}{c}\text { Nasal Greenstick } \\
\text { Fracture }\end{array}$ & Cranioplasty* & $\begin{array}{c}\text { Scar } \\
\text { Revision }\end{array}$ & \\
\hline \multicolumn{7}{|l|}{ Metopic or metopic \& sagittal technique } \\
\hline Greenstick & - & - & - & - & - & $0 / 11(0 \%)$ \\
\hline Double wedge & 5 & - & - & 1 & - & $6 / 21(29 \%)$ \\
\hline \multicolumn{7}{|c|}{ Unicoronal (no. of orbits in orbital osteotomy) } \\
\hline 1 & - & - & - & - & - & $0 / 10(0 \%)$ \\
\hline 1.5 & 7 & 1 & 1 & 3 & 1 & $13 / 34(38 \%)$ \\
\hline 2 & 1 & - & - & 1 & - & $2 / 3(66 \%)$ \\
\hline
\end{tabular}

\section{Acknowledgments}

The authors gratefully acknowledge Lindsay Bjornson for her drawings of this technical procedure. The authors would like to thank Dr. Marija Bucevska, the BCCH Plastic Surgery Research Coordinator for managing this study, Rebecca Courtemanche for her editorial assistance, and Dr. Donald G. Fitzpatrick for his clinical contributions and mentorship. We also thank the neurosurgeons who participated in clinical cases in addition to Dr. Steinbok, one of the authors: Drs. Doug Cochrane, Felix Durity, Angela Price, and Ashutosh Singhal.

\section{References}

1. Berry-Candelario J, Ridgway EB, Grondin RT, Rogers GF, Proctor MR: Endoscope-assisted strip craniectomy and postoperative helmet therapy for treatment of craniosynostosis. Neurosurg Focus 31(2):E5, 2011

2. Bottero L, Lajeunie E, Arnaud E, Marchac D, Renier D: Functional outcome after surgery for trigonocephaly. Plast Reconstr Surg 102:952-960, 1998

3. Britto JA, Gwanmesia I, Leshem D: The Christmas tree foreheadplasty: a novel technique used in combination with a bandeau for fronto-orbital remodelling in craniosynostosis. Childs Nerv Syst 28:1375-1380, 2012

4. Courtemanche DJ, Mutimer KL, Holmes AD, Levant BA, Clement JG: Experimental calvarial growth disturbance by micro-plate and screw fixation. Aust N Z J Surg 62:482488, 1992

5. Di Rocco C, Frassanito P, Tamburrini G: The shell technique: bilateral fronto-orbital reshaping in trigonocephaly. Childs Nerv Syst 29:2189-2194, 2013

6. Eppley BL, Morales L, Wood R, Pensler J, Goldstein J, Havlik RJ, et al: Resorbable PLLA-PGA plate and screw fixation in pediatric craniofacial surgery: clinical experience in 1883 patients. Plast Reconstr Surg 114:850-857, 2004

7. Erşahin Y: Endoscope-assisted repair of metopic synostosis. Childs Nerv Syst 29:2195-2199, 2013

8. Esparza J, Hinojosa J: Complications in the surgical treatment of craniosynostosis and craniofacial syndromes: apropos of 306 transcranial procedures. Childs Nerv Syst 24:1421-1430, 2008

9. Fearon JA: Beyond the bandeau: 4 variations on fronto-orbital advancements. J Craniofac Surg 19:1180-1182, 2008

10. Hinojosa J, Esparza J, García-Recuero I, Romance A: [Endoscopically assisted fronto-orbitary correction in trigonocephaly.] Cir Pediatr 20:33-38, 2007 (Span)

11. Hirabayashi S, Sugawara Y, Sakurai A, Tachi M, Harii K, Sato S: Fronto-orbital advancement by distraction: the latest modification. Ann Plast Surg 49:447-451, 2002

12. Hoffman HJ, Mohr G: Lateral canthal advancement of the supraorbital margin. A new corrective technique in the treatment of coronal synostosis. J Neurosurg 45:376-381, 1976

13. Jimenez DF, Barone CM, Cartwright CC, Baker L: Early management of craniosynostosis using endoscopic-assisted strip craniectomies and cranial orthotic molding therapy. Pediatrics 110:97-104, 2002

14. Maltese G, Tarnow P, Tovetjärn R, Kölby L: Correction of hypotelorism in isolated metopic synostosis. J Plast Surg Hand Surg 48:63-66, 2014

15. Marchac D, Renier D: Craniofacial surgery for craniosynostosis improves facial growth: a personal case review. Ann Plast Surg 14:43-54, 1985

16. Marchac D, Renier D: [The "floating forehead". Early treatment of craniofacial stenosis.] Ann Chir Plast 24:121-126, $1979(\mathrm{Fr})$

17. Marchac D, Renier D, Jones BM: Experience with the "floating forehead." Br J Plast Surg 41:1-15, 1988

18. Matic DB, Kim S: Temporal hollowing following coronal incision: a prospective, randomized, controlled trial. Plast Reconstr Surg 121:379e-385e, 2008

19. Oh AK, Greene AK, Mulliken JB, Rogers GF: Prevention of temporal depression that follows fronto-orbital advancement for craniosynostosis. J Craniofac Surg 17:980-985, 2006

20. Panchal J, Uttchin V: Management of craniosynostosis. Plast Reconstr Surg 111:2032-2049, 2003

21. Pang D, Zovickian J, Wong ST, Hou YJ, Le HN: Parallel angulated frontal bone slat cuts for treatment of metopic synostosis and other frontal skull deformities: the "cathedral dome procedure." Childs Nerv Syst 29:2171-2182, 2013

22. Pearson GD, Havlik RJ, Eppley B, Nykiel M, Sadove AM: Craniosynostosis: a single institution's outcome assessment from surgical reconstruction. J Craniofac Surg 19:65-71, 2008

23. Pellerin P, Vinchon M, Dhellemmes P, Wolber A, Guerreschi P: Trigonocephaly: Lille's surgical technique. Childs Nerv Syst 29:2183-2188, 2013

24. Persing JA: MOC-PS(SM) CME article: management considerations in the treatment of craniosynostosis. Plast Reconstr Surg 121 (4 Suppl):1-11, 2008

25. Renier D, Lajeunie E, Arnaud E, Marchac D: Management of craniosynostoses. Childs Nerv Syst 16:645-658, 2000

26. Sanger C, Soto A, Mussa F, Sanzo M, Sardo L, Donati PA, et al: Maximizing results in craniofacial surgery with bioresorbable fixation devices. J Craniofac Surg 18:926-930, 2007

27. Selber JC, Brooks C, Kurichi JE, Temmen T, Sonnad SS, Whitaker LA: Long-term results following fronto-orbital reconstruction in nonsyndromic unicoronal synostosis. Plast Reconstr Surg 121:251e-260e, 2008

28. Shimoji T, Tominaga D, Shimoji K, Miyajima M, Tasato K: Analysis of pre- and post-operative symptoms of patients 
with mild trigonocephaly using several developmental and psychological tests. Childs Nerv Syst 31:433-440, 2014

29. Steinbok P, Heran N, Hicdonmez T, Cochrane DD, Price A: Minimizing blood transfusions in the surgical correction of coronal and metopic craniosynostosis. Childs Nerv Syst 20:445-452, 2004

30. Steinbok P, Seal SKF, Courtemanche DJ: Split calvarial bone grafting in patients less than 1 year of age: technical note and use in craniofacial surgery for craniosynostosis. Childs Nerv Syst 27:1149-1152, 2011

31. Taylor JA, Tahiri Y, Paliga JT, Heuer GG: A new approach for the treatment of unilateral coronal synostosis based on distraction osteogenesis. Plast Reconstr Surg 134:176e$178 \mathrm{e}, 2014$

32. Tessier P: [Total facial osteotomy. Crouzon's syndrome, Apert's syndrome: oxycephaly, scaphocephaly, turricephaly.] Ann Chir Plast 12:273-286, 1967 (Fr)

33. Ursitti F, Fadda T, Papetti L, Pagnoni M, Nicita F, Iannetti G, et al: Evaluation and management of nonsyndromic craniosynostosis. Acta Paediatr 100:1185-1194, 2011

34. Utria AF, Mundinger GS, Bellamy JL, Zhou J, Ghasemzadeh A, Yang R, et al: The importance of timing in optimizing cranial vault remodeling in syndromic craniosynostosis. Plast Reconstr Surg [epub ahead of print], 2014

35. van der Meulen J: Metopic synostosis. Childs Nerv Syst 28:1359-1367, 2012

36. Whitaker LA, Bartlett SP, Schut L, Bruce D: Craniosynosto- sis: an analysis of the timing, treatment, and complications in 164 consecutive patients. Plast Reconstr Surg 80:195-212, 1987

37. Whitaker LA, Broennle AM, Kerr LP, Herlich A: Improvements in craniofacial reconstruction: methods evolved in 235 consecutive patients. Plast Reconstr Surg 65:561-570, 1980

38. Whitaker LA, Schut L, Kerr LP: Early surgery for isolated craniofacial dysostosis. Improvement and possible prevention of increasing deformity. Plast Reconstr Surg 60:575-581, 1977

\section{Author Contributions}

Conception and design: Courtemanche, Steinbok. Acquisition of data: Seal. Analysis and interpretation of data: all authors. Drafting the article: Seal, Steinbok. Critically revising the article: Courtemanche, Steinbok. Reviewed submitted version of manuscript: Courtemanche. Approved the final version of the manuscript on behalf of all authors: Courtemanche. Statistical analysis: Seal. Study supervision: Courtemanche, Steinbok.

\section{Correspondence}

Douglas J. Courtemanche, Division of Plastic Surgery, BC Children's Hospital, K3-131 4480 Oak St., Vancouver, BC V6H 3V4, Canada. email: douglas.courtemanche@ubc.ca. 